\title{
Full immunization coverage and its associated factors among children aged 12-23 months in Ethiopia: further analysis from the 2016 Ethiopia demographic and health survey
}

\author{
Koku Sisay Tamirat ${ }^{*}$ and Malede Mequanent Sisay
}

\begin{abstract}
Background: Vaccination is one of the cost effective strategies reducing childhood morbidity and mortality. Further improvement of immunization coverage would halt about 1.5 million additional deaths globally. Understanding the level of immunization among children is vital to design appropriate interventions. Therefore, this study aimed to assess full immunization coverage and its determinants among children aged 12-23 months in Ethiopia.

Methods: The study was based on secondary data analysis from the 2016 Ethiopia Demographic and Health Survey (EDHS). Information about 1,909 babies aged 12-23 months was extracted from children dataset. Both bivariate and multivariable logistic regression models were utilized to assess the status and factors associated with full immunization. Adjusted odds ratio (AOR) with a 95\% confidence interval (CI) was computed. Variables with less than $0.05 p$-values in the multivariable logistic regression model were considered as statistically and significantly associated with the outcome variable.

Results: The overall full immunization coverage was $38.3 \%$ (95\% Cl: 36.7, 41.2). Rural residence (AOR=0.60, 95\% Cl: $0.43,0.84$ ), employed ( $A O R=1.62,95 \% \mathrm{Cl}: 1.31,2.0)$, female household head ( $\mathrm{OOR}=0.58,95 \% \mathrm{Cl}: 0.44,0.76)$, wealth index [middle (AOR $=1.44,95 \% \mathrm{Cl}: 1.07,1.94)$ and richness ( $\mathrm{AOR}=1.65,95 \% \mathrm{Cl}: 1.25,2.19)$ ], primary school maternal education ( $\mathrm{AOR}=1.38,95 \% \mathrm{Cl}: 1.07,1.78)$, secondary school maternal education $(\mathrm{AOR}=2.19,95 \% \mathrm{Cl}: 1.43$, 3.36), diploma graduated mothers ( $\mathrm{AOR}=1.99,95 \% \mathrm{Cl}: 1.09,3.61)$, ANC follow ups ( $\mathrm{AOR}=2.79,95 \% \mathrm{Cl}: 2.173 .59$ ), and delivery at health facilities (AOR $=1.76,95 \% \mathrm{Cl}: 1.36,2.24)$ were significantly associated factors with full immunization.

Conclusion: Full immunization coverage in Ethiopia was significantly lower than the global target. Female household head and rural dwellings were negatively associated with full immunization. In contrast higher maternal education, employment, middle and rich economic status, ANC follow up, and delivery at health facility were positively associated with full immunization among 12-23 months old children. This suggests that improved health education and service expansion to remote areas are necessary to step immunization access.
\end{abstract}

Keywords: Full immunization; 12-23 months children, Associated factors, Ethiopia

\footnotetext{
* Correspondence: kokusisay23@gmail.com

Department of Epidemiology and Biostatistics, Institute of Public Health

College of Medicine and Health Sciences, University of Gondar, Gondar,

Ethiopia
}

(c) The Author(s). 2019 Open Access This article is distributed under the terms of the Creative Commons Attribution 4.0 International License (http://creativecommons.org/licenses/by/4.0/), which permits unrestricted use, distribution, and reproduction in any medium, provided you give appropriate credit to the original author(s) and the source, provide a link to the Creative Commons license, and indicate if changes were made. The Creative Commons Public Domain Dedication waiver (http://creativecommons.org/publicdomain/zero/1.0/) applies to the data made available in this article, unless otherwise stated. 


\section{Background}

Vaccination is one of the prevention strategies for common childhood illnesses. It prevents morbidities and mortalities from diphtheria, hepatitis B, measles, mumps, pertussis, pneumonia, polio, rotavirus diarrhea, rubella, cervical cancer, and tetanus [1, 2]. Vaccine preventable diseases (VPDs) account for $17 \%$ of the global under five mortality per annum [3]. According to World Health Organization (WHO) 2017 report, 116.2 million infants (85\%) received the third doses of DPT, and worldwide, 123 countries reached the third dose of diphtheria, pertussis, and tetanus (DPT3) coverage to 90\%. Despite the increasing uptake of new and underused vaccines, still an estimated 19.9 million children under the age of 1 year have not received DTP3 vaccine [1, 4-6]. Further improvement of global immunization coverage would prevent an additional 1.5 million deaths [3]. According to a case-based surveillance, the annual incidence of measles was estimated at 29.1 cases per 1 million people [7].

Expanded program of immunization (EPI) was launched by WHO in 1974 with the objectives of reducing morbidity and mortality from six VPDs. Ethiopia started the EPI program in 1980 with a longer-term goal of achieving $90 \%$ DPT3 coverage in all regions through strategies of reaching every district (RED) and sustainable outreach service (SOS) approaches. In the Ethiopia health care system, immunization is provided free of charge and services are available from the smallest health post level to the highest hospitals [8].

According to guidelines developed by the World Health Organization (WHO), children are considered fully immunized when they have received one dose of Bacillus Calmette Guerin (BCG), three doses of DPT, three doses of polio vaccines, and one dose of measles vaccination by the age of 9-12 months [9, 10]. Ethiopia has incorporated Haemophilus influenza type $\mathrm{B}(\mathrm{HiB})$ and hepatitis-B $(\mathrm{HepB})$ antigens to the previous DPT vaccines and replaced as Pentavalent vaccine (DPT plus Hep B and Hib) $[1,3,8,11]$. A variety of vaccines, of which the Pneumococcal conjugate vaccine (PCV), Rota, and Human papilloma (HPV) vaccines were the most recent have been introduced into the national EPI service overtime. Different findings showed that the proportion of full immunization coverage in the country ranged from $36.6 \%$ in Somalia region to $100 \%$ in Addis Ababa [1, 4, 10, 12-17]. Factors associated with child full immunization included socio-demographic characteristics (maternal educational status and residence), health service delivery (place of delivery, ANC follow up, vaccine availability residence, and cold chain management) [1, 4, 10, 12-22].

Although some community based works are available with different findings, no study has shown the overall national full immunization coverage after the new vaccines have been introduced into the EPI schedule. Therefore, the objective of this study was to measure the full immunization coverage and associated factors among children aged 12-23 months in Ethiopia in order to help planners assess the progress of the national full immunization coverage.

\section{Methods}

\section{Data source}

The data used in this paper is from the 2016 Ethiopian Demographic and Health Survey report. Ethiopia is the second largest populous country in Africa with 102.4 million people and an annual population growth rate of $2.5 \%$. The country is divided into nine regional and two-city administrations and has a three-tier health care system with the primary care facilities situated in nearby communities.

The two stage stratified sampling technique/ method was used for the survey. Initially, the enumeration area were stratified into urban and rural. The first stage involved selecting clusters, within the enumeration areas. The second stage was a systematic listing of households in the selected clusters. Out of each cluster 28 households were randomly selected to constitute the total sample size of households. Out of 7,193 women who gave birth in the past 5 years preceding of the survey, 5 , 980 were interviewed about the vaccination status of their children, and data gathered from 1,909 of the mothers who had children aged 12-23 months of were analyzed [23].

\section{Measurement of variables}

Full immunization was the response variable, whereas socio-demographic characteristics (age, residence, religion, marital status), reproductive health history (place of delivery, birth order, antenatal care and postnatal care follow up) were the independent variables.

The information in the 2016 EDHS report on vaccination coverage was collected from immunization cards shown to the interviewers and from mothers' verbal responses. When cards were available, the interviewer copied the vaccination dates directly onto questionnaires. When vaccination cards were not available for the child or if the vaccine was not recorded on the card as being given, the respondents were asked to recall if vaccine were given to her child.

According to the WHO guideline [1], "complete or full immunization" coverage is defined as a child that has received one dose of BCG, three doses of pentavalent, pneumococcal conjugate (PCV), oral polio vaccines (OPV); two doses of Rota virus and one dose of measles vaccine. We recoded each variable (vaccinations) as "0" and "1" for children who didn't take the recommended doses and those who took, respectively, on the basis of the reports of mothers and information in the child vaccination card. Then we added all " 0 " and " 1 "s and labeled the 
total as "Immunization status". The immunization status was recoded as "1" if the child had received all the recommended doses of all vaccinations and categorized as "full immunization" or " 0 " if the child had missed one or more doses of vaccinations and categorized as "Incomplete immunization".

\section{Statistical analysis}

Descriptive statistics were used to describe the level of full immunization coverage by socio-demographic characteristics. Bivariate and multivariable logistic regression analyses were conducted to identify the determinants of full immunization. Logistic regression was chosen because our dependent variable was dichotomous (i.e., 0 and 1). Variables in bivariable logistic regression analysis with $p$-values less than 0.2 were entered into the multivariable analysis. Adjusted odds ratio (AOR) and 95\% confidence Interval $(\mathrm{CI})$ were used to assess the strength of associations between the outcome and the independent variables. The threshold for statistical significance was set at $p<0.05$. The whole analysis was performed using STATA version 15.0.

\section{Results}

\section{Maternal and child socio-demographic characteristics}

A total of 1,909 women with children aged 12-23 months were included in the final analysis. The majority (79.2\%) women were rural dwellers and $61.1 \%$ of them had no formal education. The median age of the women was 28 (IQR: 24-33) years, and half of them were aged between 25 and 34 years; 47.3 and $31.5 \%$ were Muslims and Orthodox Christians, respectively. The poorest wealth quintile accounted for $34.3 \%$ of the participants the majority (93.5\%) whom married, and about half (51\%) of the children were male (Table 1$)$.

\section{Immunization coverage in Ethiopia}

In this study the overall full immunization coverage was 38.3\% (95\% CI: 36.7 41.2) according to the Ethiopian EPI schedule. Vaccine specific coverage for Pentavalent 3, OPV3, PCV3, Rota 2, and Measles were 56.1, 60.4, 51.9, 58 , and $57.8 \%$, respectively (Fig. 1). Full immunization coverage among rural dwellers was 31.7 and $66.6 \%$ in urban areas. Full immunization coverage was heterogeneous among Ethiopian administrative regions, ranging from $8.8 \%$ in Afar region to $86.8 \%$ in Addis Ababa (Table 2).

\section{Determinants of full immunization among children aged 12-23 months}

In the bivariable logistic regression, maternal education, residence, household head, wealth, employment, sex of household head, ANC follow-up, and parity were significant at $0.2 p$-value. In the multivariable logistic regression,
Table 1 Socio-demographic characteristics of women with children 12-23 months of age in Ethiopia, 2016 (the relationship between Women's autonomy 1909)

\begin{tabular}{|c|c|c|c|}
\hline Characteristics & Category & Frequency & Percentage \\
\hline \multirow[t]{11}{*}{ Region } & Tigray & 218 & 11.42 \\
\hline & Afar & 169 & 8.85 \\
\hline & Amhara & 178 & 9.32 \\
\hline & Oromia & 285 & 14.93 \\
\hline & Somali & 219 & 11.47 \\
\hline & $\begin{array}{l}\text { Benishangul } \\
\text { Gumz }\end{array}$ & 156 & 8.17 \\
\hline & SNNP & 226 & 11.84 \\
\hline & Gambella & 134 & 7.02 \\
\hline & Harari & 117 & 7.02 \\
\hline & Adiss Abeba & 99 & 5.19 \\
\hline & Dire Dawa & 108 & 5.66 \\
\hline \multirow[t]{2}{*}{ Residence } & Urban & 398 & 20.85 \\
\hline & Rural & 1511 & 79.15 \\
\hline \multirow[t]{3}{*}{ Age of women } & $15-24$ & 539 & 28.23 \\
\hline & $25-34$ & 971 & 50.86 \\
\hline & $35-49$ & 399 & 20.9 \\
\hline \multirow[t]{4}{*}{ Educational level } & $\begin{array}{l}\text { No formal } \\
\text { education }\end{array}$ & 1166 & 61.08 \\
\hline & $\begin{array}{l}\text { Primary } \\
\text { education }\end{array}$ & 502 & 26.3 \\
\hline & $\begin{array}{l}\text { Secondary } \\
\text { education }\end{array}$ & 156 & 8.17 \\
\hline & $\begin{array}{l}\text { Diploma and } \\
\text { higher degree }\end{array}$ & 85 & 4.45 \\
\hline \multirow[t]{2}{*}{ Sex of child } & Male & 936 & 49.03 \\
\hline & Female & 973 & 50.97 \\
\hline \multirow[t]{3}{*}{ Wealth quintile } & Poor & 975 & 51.07 \\
\hline & Middle & 278 & 14.56 \\
\hline & Rich & 656 & 34.36 \\
\hline \multirow{2}{*}{$\begin{array}{l}\text { Sex of house } \\
\text { hold head }\end{array}$} & Male & 1497 & 78.4 \\
\hline & Female & 412 & 21.6 \\
\hline \multirow[t]{2}{*}{ Marital status } & Married & 1787 & 93.5 \\
\hline & Other & 122 & 6.5 \\
\hline \multirow{2}{*}{$\begin{array}{l}\text { Employment/ } \\
\text { occupation }\end{array}$} & Yes & 795 & 41.6 \\
\hline & No & 1114 & 58.4 \\
\hline \multirow[t]{2}{*}{ Place of delivery } & Health facility & 1064 & 55.74 \\
\hline & Home & 845 & 44.26 \\
\hline \multirow[t]{4}{*}{ Religion } & Orthodox & 602 & 31.53 \\
\hline & Muslim & 913 & 47.83 \\
\hline & Protestant & 339 & 17.76 \\
\hline & Other & 55 & 2.88 \\
\hline \multirow[t]{2}{*}{ ANC follow up } & $\begin{array}{l}\text { Has ANC } \\
\text { follow up }\end{array}$ & 1227 & 64.27 \\
\hline & No ANC & 682 & 35.73 \\
\hline
\end{tabular}


Table 1 Socio-demographic characteristics of women with children 12-23 months of age in Ethiopia, 2016 (the relationship between Women's autonomy 1909) (Continued)

\begin{tabular}{llll}
\hline Characteristics & Category & Frequency & Percentage \\
\hline \multirow{4}{*}{ Birth order } & follow up & & \\
& 1 & 409 & 21.42 \\
& $2-5$ & 1022 & 53.5 \\
Postnatal care & $6+$ & 478 & 25.04 \\
& Yes & 172 & 9.01 \\
Parity & No & 1737 & 90.99 \\
& 1 & 379 & 19.8 \\
& $2-5$ & 1,046 & 54.8 \\
Child size at birth & $6+$ & 484 & 25.4 \\
& Small & 549 & 28.8 \\
& Average & 769 & 40.3 \\
& Large & 591 & 30.9 \\
\hline
\end{tabular}

only employment, residence, maternal education, wealth quintile, place of delivery, sex of household head, and ANC follow up were statistically significant at $p$-value of 0.05 .

The odds of full immunization for rural women's children decreased by $40 \%(\mathrm{AOR}=0.60,95 \%$ CI: $0.43,0.84$ ) compared to those of urban dwellers. The odds of full immunization for the children of employed mothers were $1.62(\mathrm{AOR}=1.62,95 \% \mathrm{CI}: 1.31,2.0)$ times higher compared to those of unemployed mothers. The odds of full immunization of children whose mothers had primary $(\mathrm{AOR}=1.38,95 \% \mathrm{CI}: 1.07,1.78)$ and secondary $(\mathrm{AOR}=2.19,95 \% \mathrm{CI}: 1.43,3.36)$ school as well as diploma and above $(\mathrm{AOR}=1.99,95 \% \mathrm{CI}: 1.09,3.61)$ level of educational were higher than those of children whose mothers had no formal education. For women who had middle and rich wealth status the odds of full immunization of children were 1.44 $(\mathrm{AOR}=1.44,95 \%$ CI: $1.07,1.94)$ and $1.65(\mathrm{AOR}=1.65,95 \% \mathrm{CI}: 1.25,2.19)$
Table 2 Full immunization coverage among children aged 1223 months in the Regional administrations of Ethiopia, 2016 $(n=744)$

\begin{tabular}{lll}
\hline Regions & Frequency & Percentage \\
\hline Tigray & 138 & 63.3 \\
Afar & 15 & 8.8 \\
Amhara & 74 & 41.6 \\
Oromia & 73 & 25.6 \\
Somali & 44 & 20.1 \\
Benishangul Gumz & 82 & 52.6 \\
SNNP & 74 & 32.7 \\
Gambella & 36 & 26.8 \\
Harari & 56 & 42.7 \\
Adiss Abeba & 86 & 86.8 \\
Dire Dawa & 72 & 66.6 \\
\hline
\end{tabular}

times higher compared to those of poorer mothers. The odds of full immunization of children whose mothers had ANC follow ups during pregnancy were 2.79 $(\mathrm{AOR}=2.79,95 \% \mathrm{CI}: 2.17,3.59)$ higher than those of children whose mothers had no follow ups. For women who delivered in health facilities, the odds of full immunization of children were 1.76 (AOR $=1.76,95 \%$ CI: $1.38,2.24)$ times higher compared to those of children whose mothers delivered at home. The odds of full immunization of children whose household heads were female were $42 \%$ (AOR $=0.58,95 \%$ CI: 0.44, 0.76) lower than those of their counterparts (Table 3).

\section{Discussion}

This study revealed that the overall full immunization coverage of Ethiopia was 38.3\%, much lower than the $86 \%$ Government report and less promising to meet the 2020 health sector transformation plan of $95 \%[8,23]$. Vaccine specific full immunization coverage's among children were $56.1 \%$ for Pentavalent third dose and 57.8\% for Measles,

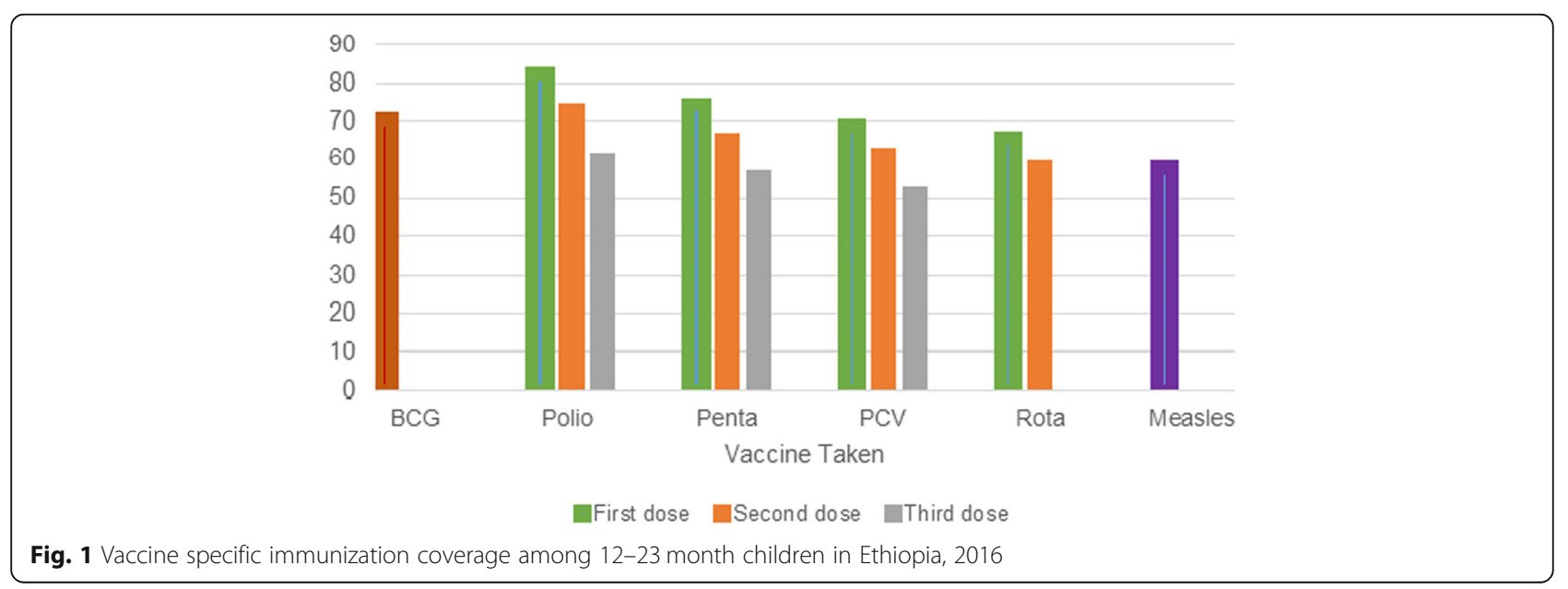


Table 3 Bivariable and multivariable logistic regression analysis to identify factors associated with fully immunization among women with 12-23 month children in Ethiopia, 2016

\begin{tabular}{|c|c|c|c|c|}
\hline \multirow[t]{2}{*}{ Variables } & \multicolumn{2}{|c|}{$\begin{array}{l}\text { Full } \\
\text { Immunization }\end{array}$} & \multirow[t]{2}{*}{$\begin{array}{l}\text { Crude odds ratio } \\
\text { (OR } 95 \% \mathrm{Cl} \text { ) }\end{array}$} & \multirow[t]{2}{*}{$\begin{array}{l}\text { Adjusted odds ratio } \\
\text { (OR 95\% Cl) }\end{array}$} \\
\hline & Yes & No & & \\
\hline \multicolumn{5}{|l|}{ ANC follow up } \\
\hline Yes & 624 & 603 & $4.84(3.866 .07)$ & $2.79(2.173 .59)^{*}$ \\
\hline No & 120 & 562 & 1 & 1 \\
\hline \multicolumn{5}{|l|}{ Place of residence } \\
\hline Urban & 265 & 133 & 1 & 1 \\
\hline Rural & 479 & 1032 & $0.23(0.180 .29)$ & $0.60(0.430 .84)^{*}$ \\
\hline \multicolumn{5}{|l|}{ Place of delivery } \\
\hline Health facility & 480 & 365 & $3.98(3.284 .84)$ & $1.76(1.362 .24)^{*}$ \\
\hline Home & 264 & 800 & 1 & 1 \\
\hline \multicolumn{5}{|l|}{ Educational level } \\
\hline No education & 333 & 833 & 1 & 1 \\
\hline Primary & 241 & 261 & $2.3(1.862 .86)$ & $1.38(1.071 .78)^{*}$ \\
\hline Secondary & 105 & 51 & 5.15(3.60 7.36) & $2.19(1.433 .36)^{*}$ \\
\hline Tertiary & 65 & 20 & 8.13(4.84 13.36) & $1.99(1.093 .61)^{*}$ \\
\hline \multicolumn{5}{|l|}{ Household head } \\
\hline Male & 889 & 608 & 1 & 1 \\
\hline Female & 276 & 136 & $0.72(0.570 .90)$ & $0.58(0.440 .76)^{*}$ \\
\hline \multicolumn{5}{|l|}{ Wealth quintile } \\
\hline Poor & 248 & 727 & 1 & 1 \\
\hline Middle & 110 & 168 & $1.91(1.452 .54)$ & $1.44(1.07,1.94)^{*}$ \\
\hline Rich & 386 & 270 & 4.19(3.39 5.18) & $1.65(1.252 .19)^{*}$ \\
\hline \multicolumn{5}{|l|}{ Employment } \\
\hline No & 743 & 371 & 1 & 1 \\
\hline Yes & 422 & 373 & $1.77(1.462 .13)$ & $1.62(1.312 .0)^{*}$ \\
\hline \multicolumn{5}{|l|}{ Parity } \\
\hline 1 & 187 & 192 & 1 & 1 \\
\hline $2-5$ & 419 & 627 & $0.68(0.540 .86)$ & $1.13(0.851 .50)$ \\
\hline $6+$ & 138 & 346 & $0.41(0.300 .54)$ & $0.99(0.701 .41)$ \\
\hline
\end{tabular}

*shows a $p$-value less than 0.05

below the Federal Ministry of Health 2015 report of 94\% for both of them [8]. The possible reasons for the discrepancies between the national reports and this study might be spurious and false reports from health facilities.

This study also showed differences between full immunization and vaccine specific full dose coverage's. The possible explanations for the variations might be the stock out of vaccines and the side effects of multiple injections. Furthermore as shown in the Table 2, full immunization coverage was in Ethiopia highly varies among administrative regions, ranging from $8.8 \%$ in Afar to $86.8 \%$ in Addis Ababa. The possible reasons might be socio-demographic and health seeking behavior differences among regions. In addition, most of the regions with low full immunization coverage had weak health care systems which led to low uptake of vaccines. Moreover, some of the regions like Afar and Somalia had hard to reach areas are nomadic and pastoralist inhabitants with no permanent residence.

This finding of full immunization coverage was lower than those of studies conducted in Togo (63.7\%), Cameroon (53.6\%), Timor-Leste (52.6\%), Uganda (52.5\%), Coted'Ivoire (50.5\%) DR Congo (49.8\%), and Haiti (45.8\%) [1, 4, 20, 24, 25]. It was higher than findings in Somalia (11.6\%), Mauritania (35.3), Nigeria (33.2\%), Chad (11.4\%), and the Republic of Central Africa $(17.3 \%)[25,26]$. The possible explanations might be differences in study periods and number of vaccines Like PCV and Rota incorporated in the expanded program of immunization of Ethiopia. Health system differences among countries are also possible explanations for the observed differences. The full immunization coverage finding in this study was significantly higher than 2005 and 2011 EDHS reports of 19 and 24\%, respectively [14]. This might be due to tremendous efforts of the Government to realize the millennium development goal of reducing child mortality from vaccine preventable diseases.

Maternal characteristics, residence, educational level, sex of household head, employment, wealth index, ANC follow up and place of delivery were factors associated with full immunization coverage among 12-23 months of age children. Rural residence was associated with lower full immunization of children compared to urban dwellings. This finding is in agreement with those of studies conducted in Arbaminch, Lay Armachio, and Jigijiga of Ethiopia, and Nigeria [9, 13, 14, 17]. This might be due to less accessibility of health facilities to EPI and differences in awareness about immunization. Maternal educational status of primary school and above associated with an increased full immunization of children. This finding is in agreement with the results of previous studies conducted in Ethiopia, Togo, Arbaminch, and Southwest Ethiopia [14, 17, 27-29]. The full immunization of children with female household heads was lower compared to children who had male household heads. This might be because of high workload and family responsibilities women may not heed EPI schedules for children vaccination. This finding was supported by that of a study conducted in Togo [20]. The full immunization of children whose mothers had ANC follow ups was three times higher than that of children whose mothers had no follow ups. This is supported by the results of previous studies conducted in Togo and Ethiopia [10, 12, 20, 30]. This might be because women who attend follow ANC may get counseling about child immunization in the postnatal period. The children of middle income and rich mothers were associated with higher full immunization than the children of poor 
mothers. This might be due to differences in child care practice, better health seeking behavior, and health care access. This finding was supported by studies conducted in Nigeria, Togo, and Southwest Ethiopia [9, 12, 14, 20, 22, 29]. The children of women who delivered at health facilities were two times more likely to receive full immunization compared to those of women who had home delivery. This finding was concordat with those of studies in Nigeria and Ethiopia [9, 17, 20, 22, 30]. This might be due to the fact that some vaccines, like BCG and OPV 0 are often given immediately after birth at health facilities. The children of employed mothers were associated with increased fully immunization compared to those of unemployed ones. This might be due to better information access about disease preventions, like immunization.

Sine not all children had vaccination cards, information about immunization status had to be limited the mothers' verbal responses which were found to be prone to recall bias. Besides, having been based on secondary data analysis, this survey could not assess factors relating to the supply side and health system.

\section{Conclusion}

Full immunization coverage in Ethiopia was significantly lower than the global target. Female household head and rural dwelling were negatively associated with full immunization. In contrast higher maternal education, employment, middle and rich economic status, ANC follow up, and delivery at health facility were positively associated with full immunization among 12-23 months old children. This suggests that improved health education and service expansion to remote areas are necessary to step immunization access.

\section{Abbreviations \\ ANC: Antenatal care; AOR: Adjusted odds ratio; BCG: Bacilli Calamite Guerin; DPT: Diphtheria, pertussis, and tetanus; EA: Enumeration area; EDHS: Ethiopia Demography Health Survey; EPI: Expanded program of immunization; IQR: Interquartile range; OPV: Oral polio vaccine; OR: Odds ratio; \\ PCV: Pneumococcal conjugate vaccine; PHC: Population and housing census; RED: Reaching every district; SNNP: South Nation's Nationalities and Peoples; SOS: Sustainable outreach service; USD: US dollar; VPD: Vaccine preventable disease; WHO: World Health Organization}

\section{Acknowledgments}

We would like to thank the Ethiopian Central Statistics Agency for providing me with all the relevant secondary data used in this study. Finally, we would like to thank all who directly or indirectly supported us.

\section{Authors' contributions}

KST and MMS conceived the study, involved in the study design, data analysis, drafted the manuscript and critically reviewed the manuscript. Both authors read and approved the final manuscript.

\section{Funding}

We didn't received external fund for this research.

\section{Availability of data and materials}

The datasets used during the current study is available from the corresponding author on reasonable request.

\section{Ethics approval and consent to participate}

Ethical clearance was obtained from measure DHS through filling requesting form for accessing data. The data used in this study are publicly available, aggregated secondary data which hasn't any personal identifying information that can be linked to study participants. Confidentiality of data was maintained anonymously.

\section{Consent for publication}

Not applicable as there is no image or other confidentiality related issues.

\section{Competing interests}

The authors declare that they have no competing interests.

Received: 17 January 2019 Accepted: 22 July 2019

Published online: 30 July 2019

\section{References}

1. World Health Organization, Immunization, vaccines, and biologicals: implementation research in immunization. 2017.

2. Wondwossen, L., et al., Advances in the control of vaccine preventable diseases in Ethiopia. 2017, African Field Epidemiology Network.

3. Plan GVA. Decade of vaccines global vaccine action Plan GVAP secretariat report 2015, vol. 22: SAGE; 2015.

4. LaFond $A$, et al. Drivers of routine immunization coverage improvement in Africa: findings from district-level case studies. Health Policy Plan. 2014;30(3): 298-308.

5. Teferi E. Factors influencing coverage and key challenges to achieving targets of routine immunization in Africa: a systematic review. Ethiop J PediatrChild Health. 2016;12(2):31-42.

6. Duclos P, et al. Global immunization: status, progress, challenges and future. BMC Int Health Hum Rights. 2009:9.

7. Masresha B, et al. Status of measles elimination in eleven countries with high routine immunisation coverage in the WHO African region. J Immunol Sci. 2018:140.

8. Fedral Ministry of Health, Ethiopia National Expanded Programme on Immunization. 2015: Addis Ababa.

9. Animaw $W$, et al. Expanded program of immunization coverage and associated factors among children age 12-23 months in Arba Minch town and Zuria District, Southern Ethiopia, 2013. BMC Public Health. 2014;14(1):464.

10. Dessie $D B$, Negeri MA. Determining factors of full immunization of children among 12-23 months old in rural Ethiopia. Am J Public Health. 2018;6(3):160-5.

11. Cherian T, Okwo-Bele J-M. The decade of vaccines global vaccine action plan: shaping immunization programmes in the current decade: Taylor \& Francis; 2014.

12. Asmamaw A, et al. Determinants of full valid vaccine dose administration among 12-32 months children in Ethiopia: evidence from the Ethiopian 2012 national immunization coverage survey. Ethiop J Health Dev. 2016; 30(3):135-41.

13. Kassahun MB, Biks GA, Teferra AS. Level of immunization coverage and associated factors among children aged 12-23 months in lay Armachiho District, North Gondar zone, Northwest Ethiopia: a community based cross sectional study. BMC Res Notes. 2015;8(1):239.

14. Lakew Y, Bekele A, Biadgilign S. Factors influencing full immunization coverage among 12-23 months of age children in Ethiopia: evidence from the national demographic and health survey in 2011. BMC Public Health. 2015;15(1):728.

15. Meleko A, Geremew M, Birhanu F. Assessment of child immunization coverage and associated factors with full vaccination among children aged 12-23 months at Mizan Aman town, bench Maji zone, Southwest Ethiopia. Int J Pediatr. 2017;2017.

16. Mohammed H, Atomsa A. Assessment of child immunization coverage and associated factors in Oromia regional state, eastern Ethiopia. Sci Technol Arts Res J. 2013;2(1):36-41.

17. Mohamud AN, et al. Immunization coverage of 12-23 months old children and associated factors in Jigjiga District, Somali National Regional State, Ethiopia. BMC Public Health. 2014;14(1):865.

18. Bekele AT, et al. Factors contributing to routine immunization performance in Ethiopia, 2014. The Pan African medical journal. 2017;27(Suppl 2).

19. Ebot JO. "Girl power!": the relationship between Women's autonomy and Children's immunization coverage in Ethiopia. J Health Popul Nutr. 2015; 33(1):18. 
20. Landoh DE, et al. Predictors of incomplete immunization coverage among one to five years old children in Togo. BMC Public Health. 2016;16(1):968.

21. Okwaraji YB, et al. The association between travel time to health facilities and childhood vaccine coverage in rural Ethiopia. A community based cross sectional study. BMC Public Health. 2012;12(1):476.

22. Oleribe $\mathrm{O}$, et al. Individual and socioeconomic factors associated with childhood immunization coverage in Nigeria. Pan Afr Med J. 2017;26.

23. Central Statistical Agency (CSA) [Ethiopia] and ICF. Ethiopia demographic and health survey 2016: HIV Report [Ethiopia]. Addis Ababa, Ethiopia, and Rockville, Maryland, USA: CSA and ICF; 2016.

24. Fatiregun AA, Okoro AO. Maternal determinants of complete child immunization among children aged 12-23 months in a southern district of Nigeria. Vaccine. 2012;30(4):730-6.

25. Restrepo-Méndez MC, et al. Missed opportunities in full immunization coverage: findings from low-and lower-middle-income countries. Glob Health Action. 2016;9(1):30963.

26. Restrepo-Méndez MC, et al. Inequalities in full immunization coverage: trends in low-and middle-income countries. Bull World Health Organ. 2016; 94(11):794.

27. Sanou A, et al. Assessment of factors associated with complete immunization coverage in children aged 12-23 months: a cross-sectional study in Nouna district, Burkina Faso. BMC Int Health Hum Rights. 2009;9(1):S10.

28. Tadesse $H$, Deribew A, Woldie M. Predictors of defaulting from completion of child immunization in South Ethiopia, may 2008-a case control study. BMC Public Health. 2009;9(1):150.

29. Wado YD, Afework MF, Hindin MJ. Childhood vaccination in rural southwestern Ethiopia: the nexus with demographic factors and women's autonomy. Pan Afr Med J. 2014;17(Suppl 1).

30. Abadura SA, et al. Individual and community level determinants of childhood full immunization in Ethiopia: a multilevel analysis. BMC Public Health. 2015;15(1):972.

\section{Publisher's Note}

Springer Nature remains neutral with regard to jurisdictional claims in published maps and institutional affiliations.

Ready to submit your research? Choose BMC and benefit from:

- fast, convenient online submission

- thorough peer review by experienced researchers in your field

- rapid publication on acceptance

- support for research data, including large and complex data types

- gold Open Access which fosters wider collaboration and increased citations

- maximum visibility for your research: over $100 \mathrm{M}$ website views per year

At $\mathrm{BMC}$, research is always in progress.

Learn more biomedcentral.com/submissions 